\title{
Lean Manufacturing: Selected Financial Performance Of Recognized Lean Manufacturers
}

Mehmet C. Kocakulah, (E-mail: Mkocakul@Usi.edu), University of Southern Indiana Jim Upson, (E-mail: upsonj1 @ insightbb.com), University of Southern Indiana

\begin{abstract}
Since the Japanese development of lean manufacturing practices after World War II, American companies have slowly begun to embrace the concepts and results offered by the lean manufacturing concept. Companies in America did not fully embrace the value of the processes until the mid to late 1990's and some firms are finding that financial results that should have been positively impacted immediately are not showing the results promised by Japanese practitioners. Two companies, Delphi and Johnson Controls, were selected for comparative analysis because of the numerous facilities that each have had selected for the Shingo Prize for Excellence in Manufacturing. Both companies have been engrained in the traditional mass-producing methods of American production from mother companies, customers, and suppliers. Both companies have adopted and implemented lean manufacturing into their organizations in the late 1990's. Using targets set forth by the lean manufacturing leaders of Japan, a comparison will be made of both of these companies as well as comparisons of these two companies to other firms in their industry. The S\&P 500 financial ratios will also be used along with those of two of the most recognized leaders in lean manufacturing, Wal-Mart and Toyota, in order to determine the effectiveness of implementation of lean practices by two of the newest leaders in manufacturing excellence. The financial ratios will be evaluated and compared along with reasons for variances that are found in the comparisons.
\end{abstract}

\section{HISTORY OF LEAN}

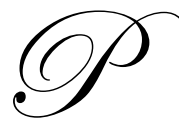

articipation in World War II required great industrial output such as the production of tanks and planes from American manufacturers. After the war ended, the manufacturing and demand situation in America greatly differed from those in Japan. American manufacturers produced standard products in mass quantities. Japan was faced with declining materials and low financial resources so they chose alternate, less costly methods to manufacture products. Since Japan did not have the infrastructures to compete with the larger producers in America, such as Ford Motor Company, they concentrated on selling smaller quantities of cars in their own country. The Japan Manufacturing System, a system developed by Eiji Toyoda, Taiichi Ohno, and Shingeo Shingo (MAMTC), was developed to minimize the consumption of resources in the manufacturing of the automobiles and allowed Japan to compete with mass producers in America. It was not until after the oil crisis of 1973 that America started to take notice of the manufacturing systems in Japan. The publishing of "The Machine That Changed the World" highlighted the accomplishments of Japan's only growth company of the times (MAMTC).

\section{GOALS OF LEAN}

The primary goals of the lean manufacturing system are to make dramatic improvements in the areas of quality, inventory reductions, production lead times, and costs reductions. These goals are focused around eliminating "muda" (waste), establishing organization (5S), standardizing work practices, and enabling total productive maintenance. 
A primary step in the implementation of lean manufacturing is the $5 \mathrm{~S}$ system. The $5 \mathrm{~S}$ 's in the system are Sort (Seiri), straighten (Seiton), scrub (Seiso), systematize (Seiketso), and sustain (Shitsuke). Most of the steps are simple in definition but are sometimes difficult for companies to implement. The sorting steps are to eliminate all waste and unnecessary steps in the process. Other items should be straightened and clearly marked for identification and arranged in kanban squares for easy access and identification of location. Scrubbing the facility is done to maintain a clean and safe work area and the systematization serves to organize the work area. Once all of these steps have been realized the final and most difficult step is to sustain the successes of the first four steps.

There are other goals, in addition to the 5S System, that need to be fully addressed in order to achieve the benefits of lean production systems (MAMTC). Instituting a JIT system that creates product only based on customer demand helps to reduce inventories, therefore, reducing overall costs. Employee involvement and empowering teams are critical in making the processes work smoothly and the use of visual management is used to track the performance of the process and to motivate employees.

Lean manufacturing aims to meet the customer's needs through target costing. Target costing can meet pricing needs of customers and can be achieved once all unnecessary steps and waste have been eliminated from the process. Continuous improvement is the ongoing legacy of a lean manufacturing system that has the goal of reaching perfection and continuous improvement projects are the means to which the goal becomes a closer target.

\section{METHODS \& EXPECTED BENEFITS OF LEAN V MASS}

There are seven main areas that are useful to analyze for each type of production method: culture, customer satisfaction, engineering, leadership, maintenance, organization, and production (PPI, Cre8tive Training Inc.). Mass production requires customer loyalty and obedience towards products while lean production relies on customer input and feedback which helps ensure the quality of products. Customer satisfaction in lean production includes producing what customers want/demand, zero product defects, and timely production of customer demanded products. Mass produced products are made according to standard specifications and are produced in large quantities that create large amounts of slow moving inventory.

The engineering of products differ in lean manufacturing. While mass production includes little input from customers, the engineering of a product for lean production includes team-based models, high input from customers, and continual development of product and production processes. In lean production, there is a team-based environment, flat hierarchies, and leadership carried out by the teams. Lean production also differs from mass production in the areas of machine size, equipment management and maintenance by all employees, cell-type layout (more efficient), cross-functional training (employees obtain multiple skills), and zero inventories. Cost reductions attributed to lean manufacturing include faster cycle times and waste reductions enabling lower inventory levels than mass production facilities. This can lead to a reduction of $35-55 \%$ of manufacturing space. Another advantage offered from a lean system is a preventative maintenance programs that serves to extend equipment life. This will delay the need for new equipment and raise the available time a piece of equipment can be used for producing a part. (Henderson 22).

\section{COMPANY EVALUATION METHOD}

The expected results from a company that has adopted the lean philosophy and methods include increased inventory turnover rates, improved quality performance, improved delivery performance, reduced product lead times, reduced conversion costs, smaller plants, reduced new product introduction times, and improved productivity. Financial reports for companies reflect these ratios and metrics in the quarterly or annual financial reports. A comparison can be made of companies who have adopted the philosophy and methods of lean manufacturing by using these financial yardsticks to assess the success of the leanness of the company.

A comparison of some newcomers to the lean manufacturing methods will be evaluated both quantitatively and qualitatively. Inventory turnover rates for the companies are given in financial reports and will be directly compared to industry averages, S\&P 500 results, and key benchmark lean producers such as Toyota and Wal-Mart. 
Improved quality performance will be assessed qualitatively by noting recent quality awards and recognitions that companies have received. Reduced product delivery times will be assessed based on inventory turnover rates and inventory valuations from company balance sheets. Conversion costs will be measured based on income per employee, revenue per employee, and return on assets. Reduced new product introduction times will be measured qualitatively based on awards and press announcements. Finally, improved productivity will be measured based on income per employee and return on capital. In addition, stock performance, cash flow, and the quick ratio of the company will be used to assess the overall financial effectiveness of lean manufacturing. Some measures, which are positive products of an effective lean manufacturing firm, are difficult to quantify. Delivery performance and plant size are difficult to track for a company due to the lack of sufficient information; therefore, these metrics will not be used in the evaluation.

\section{SELECTION OF METRICS}

Table 1 summarizes the metrics that were selected for each expected result of adopting lean manufacturing methods. The selection criteria for each metric was based on the perceived degree of measurement validity, the availability of the data, and whether the qualitative assessment was considered to be an indicator of the quantitative performance. For example, inventory turnover rates are a direct measure of the expected reduction in finished good inventories created by lean manufacturing practices. Quality performance data can be measured in a number of qualitative ways including PPM, C/100, or warranty repairs. However, because this qualitative data was not available, quality awards were considered to be a good indicator of quality performance. No direct measure was available for production lead times, however, inventory turnover rates and balance sheet valuations of finished goods inventory were considered to be good indicators of lead-time reductions. Income and revenue per employee and return on assets were selected to compare conversion costs because they are direct measures of production and management efficiency (Jordan 59). Quantitative information was not available for product development time but awards and press releases of new products were considered to be a fair indication of product development effectiveness. Finally, productivity was measured in terms of income per employee and return on capital. Return on capital was selected because it indicates how well a company will do with additional capital investment (Price). Return on capital is calculated as ROE/ (1+DTE). Based on this equation the debt position of a company is also included in the calculation of the return. Selected metrics were compared to industry averages, performance of the S\&P 500, and performance for two generally recognized lean practitioners: Toyota and Wal-Mart.

Table 1: Lean manufacturing evaluation metrics

\begin{tabular}{|c|c|c|c|}
\hline Result & Targets & Metric & Reason \\
\hline $\begin{array}{l}\text { Inventory Turnover } \\
\text { Rates }\end{array}$ & $>50$ & Inventory turnover rate & Direct measure \\
\hline Quality Performance & $<3$ ppm & Awards and press releases & No qualitative data available \\
\hline Improved Delivery & $100 \%$ & None & No qualitative data available \\
\hline $\begin{array}{l}\text { Reduced Production } \\
\text { Lead Times }\end{array}$ & $<1$ day & $\begin{array}{l}\text { Inventory turnover rates and } \\
\text { valuations }\end{array}$ & Indirect measure \\
\hline $\begin{array}{l}\text { Reduced conversion } \\
\text { costs }\end{array}$ & $>25 \%$ Reduction & $\begin{array}{l}\text { Income/revenue per } \\
\text { employee and return on } \\
\text { assets }\end{array}$ & Direct measure \\
\hline Smaller Plants & none & None & No qualitative data available \\
\hline $\begin{array}{l}\text { Reduced new product } \\
\text { introduction times }\end{array}$ & $<6$ months & Awards and press releases & No qualitative data available \\
\hline Improved productivity & Better than Industry & $\begin{array}{l}\text { Income per employee and } \\
\text { return on capital }\end{array}$ & Direct measure \\
\hline
\end{tabular}

\section{SELECTION CRITERIA FOR COMPANIES}

Three selection criteria were used to select the companies used to evaluate the financial performance implications of adopting lean manufacturing systems. The first criterion was that the company had been independently recognized as effectively implementing lean manufacturing practices. Many companies claim that 
they are lean manufacturers, but without an external confirmation, the contention may not be well founded. Based on this criterion, only companies that have been awarded the Shingo Prize for Excellence in Manufacturing were considered for analysis. The Shingo Prize was founded in 1988 to recognize leaders in lean manufacturing and is considered "the Nobel Prize of manufacturing" (Shingo Prize).

The second criterion was that the company be publicly traded in order to facilitate access to relevant financial information. Finally, the company could not be experiencing any external problems that would mask the performance results of adopting a lean manufacturing system. For example, Federal-Mogul was rejected as a company for consideration because they had recently filed for bankruptcy due to asbestos claims.

Based on these criteria Delphi Corporation and Johnson Controls were selected for evaluation.

\section{DELPHI CORPORATION}

Delphi Corporation (formerly Delphi Automotive Systems) was created as a spin-off corporation from General Motors in 1999. Delphi, a Tier 1 parts supplier that is serviced by numerous Tier 2 and Tier 3 suppliers, is the world's largest automotive parts manufacturer. Delphi's primary customer is GM which accounted for roughly $\$ 17.9$ billion of Delphi's \$27.4 billion in sales. Although GM represents almost 2/3 of Delphi's sales, Delphi has been successfully diversifying its customer base, growing sales to other customers from $\$ 6.8$ billion in 1999 to $\$ 9.5$ billion in 2002. Delphi makes a diverse array of automotive parts including power train, suspension, electronic controls and devices, and interior components (MSN Money).

\section{Delphi: Commitment to Lean}

Delphi, an independent company from GM since 1999, has had twelve plants receive the Shingo Prize (Shingo Prize). Table 2 shows the years and number of plants that have been awarded the prize. Delphi's recognition rate as a leader in adopting lean manufacturing practices has been increasing as can be seen in Table 2. Delphi is represented by 167 world wide manufacturing facilities but the Shingo prize is limited to only those facilities in Canada, Mexico, and the US. Delphi has 68 manufacturing facilities in the US, Canada, and Mexico of which 12 have been recognized. This accounts for $18 \%$ of the eligible Delphi operations receiving the award for being a leader in lean processes. In addition, Delphi is expanding their implementation of lean practices to include their supply chain (Jewett 48). Based on this information Delphi's commitment and achievements in implementing lean manufacturing systems makes it an ideal company for analyzing the financial impacts of adopting the lean approach.

Table 2: Shingo Awards to Delphi Year 19992000200120022003 Total

\begin{tabular}{lllllll}
\hline \# of Plants & 1 & 2 & 0 & 5 & 4 & 12
\end{tabular}

\section{Delphi: Presentation of Metrics and Comments}

Table 3 indicates the inventory turnover rates for Delphi and compares them with several other standards (MSN Money). Relative to the auto parts industry, Delphi's inventory turnover rate of 14.6 is slightly above average and exceeds the other selected standards. However, relative to the lean manufacturing target shown in Table 1 of inventory turnovers exceeding 50 turns per year, Delphi is well short of this lean target. Inventory turnover is defined as cost of sales for the past 12 months divided by the average inventory. 


\begin{tabular}{cccccc}
\multicolumn{2}{c}{ Table 3: Delphi Inventory Comparison } \\
(Source: MSN Money) & & \\
& Delphi & Industry & S\&P 500 & Toyota & Wal-Mart \\
\cline { 2 - 7 } Inventory Turns & 14.6 & 12.7 & 7.7 & 11.1 & 7.9
\end{tabular}

Although there are numerous quality citations that have been awarded to Delphi over the past years, three recent awards are good indicators of Delphi's quality performance. First, on March 26 of 2003, Toyota recognized Delphi for meeting or exceeding the quality and delivery requirements of Toyota (Delphi). Second, Delphi was recognized by Subaru-Isuzu for quality achievements on three products on May 1. The products were an evaporative emissions canister, air meters, and oxygen sensors. Finally, Delphi was awarded two masters of quality awards from Freightliner on May 29, 2003. These masters of quality awards signify that Delphi had met strict quality standards and that Delphi demonstrated a continuing commitment to quality improvement. Although no quality trend data was available, these awards indicate that Delphi has achieved a recognized high level of quality output.

As lean manufacturing methods are implemented, production lead times are expected to drop significantly with respect to mass production methods. Reduced production lead times should result in both a reduction in finished goods and in total inventory including work in process and supplies. Table 4 indicates the trend data for finished goods inventory and net inventory valuations for Delphi (Delphi). Finished goods valuations have been increasing even though price pressure on automotive suppliers has been in the negative direction. In addition, estimated inventory turns, Net Sales divided by Net Inventory Value, have been decreasing. Chart 1 indicated the trend of finished goods inventory evaluations and the percent of Net Inventory Value relative to Net Sales. Both of these trends are increasing. This would imply that inventories are also increasing and by extension that production lead times are either increasing or becoming less stable. Although there may be many causes to the increase in inventory value for Delphi, lean manufacturing does not seem to be adding major benefits in this area.

Table 4: Delphi Inventory Valuations

\begin{tabular}{|c|c|c|c|c|c|}
\hline Year & $\begin{array}{c}\text { Finished } \\
\text { Goods } \\
\text { (Millions \$) }\end{array}$ & $\begin{array}{c}\text { Net } \\
\text { Inventory } \\
\text { Value } \\
\text { (Millions \$) }\end{array}$ & $\begin{array}{l}\text { Net Sales } \\
\text { (Millions \$) }\end{array}$ & $\begin{array}{c}\text { Net } \\
\text { Inventory } \\
\text { as } \% \text { of } \\
\text { net sales }\end{array}$ & $\begin{array}{c}\text { Estimated } \\
\text { Inventory } \\
\text { Turns } \\
\end{array}$ \\
\hline$\overline{1999}$ & 263.0 & 1749.0 & 29,192 & $5.99 \%$ & 16.7 \\
\hline 2000 & 314.0 & 1707.0 & 29,139 & $5.86 \%$ & 17.1 \\
\hline 2001 & 313.0 & 1621.0 & 26,088 & $6.21 \%$ & 16.1 \\
\hline 2002 & 435.0 & 1769.0 & 27,427 & $6.45 \%$ & 15.5 \\
\hline
\end{tabular}

As indicated in Table 1, conversion cost for products should be reduced by $25 \%$ or more. Table 5 shows the metric comparison for evaluating conversion costs (MSN Money). Clearly, Delphi lags all other standards in income per employee and revenue per employee. Delphi is also below the industry average for return on assets and although they are higher in this metric than Toyota, the total assets employed by Delphi are likely to be much lower. These numbers indicate that Delphi has not yet realized the expected reduction in conversion costs from adopting lean manufacturing.

Although there is no direct measurement for reductions in the time to market metric, Delphi has received numerous awards for their product development. On May 14, 2003 Delphi received 5 Environmental Excellence in Transportation awards from SAE. These awards were for new products, new engineering methods, new process developments, and process refinements. In addition, Delphi was ranked number one by MIT's Technology Review magazine for its technological advancements in the automotive industry (Delphi). One of the categories used in determining the ranking is the technology cycle time; the time required to leading edge advances into intellectual 
property. Delphi introduced 184 new products and/or processes in 2002 representing a 47\% increase over 2001. Delphi has indicated that their pace of new product introductions will increase over the next few years (Delphi).

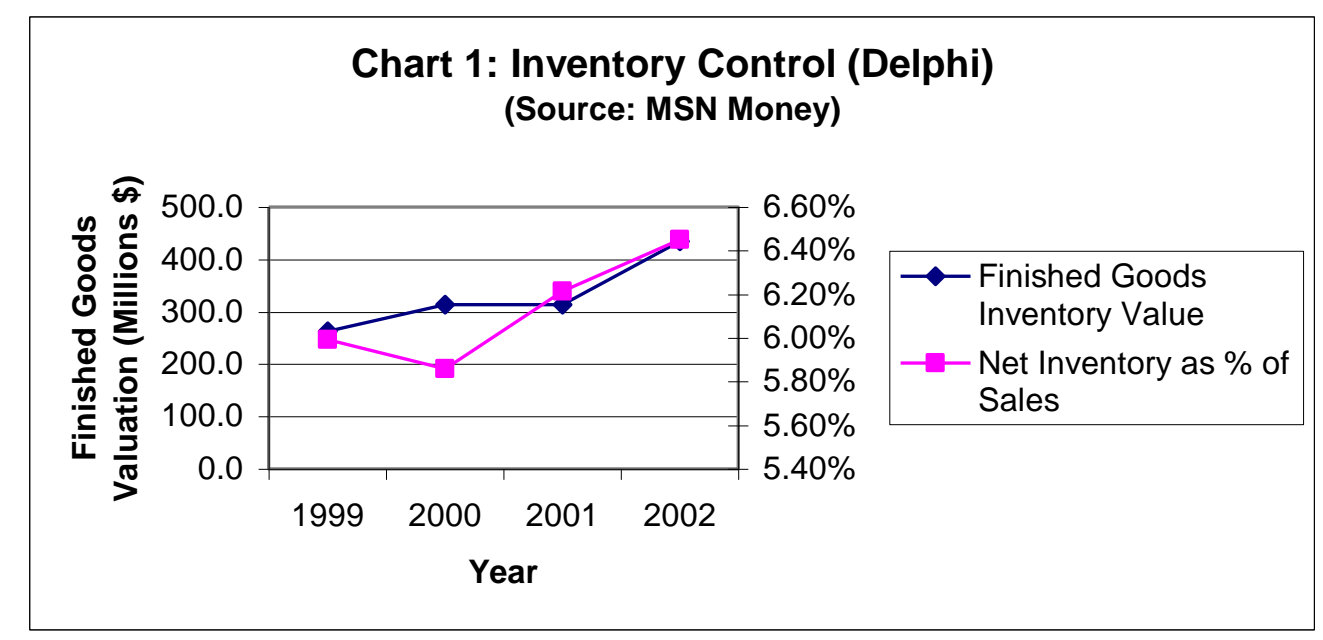

Table 5: Delphi Conversion Cost Comparison

(Source: MSN Money)

\begin{tabular}{l|cccccc}
\multicolumn{1}{c}{} & \multicolumn{2}{c}{ (Source: MSN Money) } & & \\
& Delphi & Industry & S\&P 500 & Toyota & Wal-Mart \\
\cline { 2 - 7 } Income per Employee & $\$ 3,000$ & $\$ 4,000$ & $\$ 12,000$ & $\$ 17,000$ & $\$ 6,000$ \\
Revenue per Employee & $\$ 145,000$ & $\$ 170,000$ & $\$ 290,000$ & $\$ 436,000$ & $\$ 175,000$ \\
Return on Assets & $2.7 \%$ & $3.2 \%$ & $1.3 \%$ & $2.9 \%$ & $8.5 \%$ \\
Return on Capital & $14.8 \%$ & $7.1 \%$ & $3.6 \%$ & $5.1 \%$ & $13.6 \%$
\end{tabular}

Productivity metrics are also shown in Table 5. While Delphi's income per employee is below all other standards, Delphi's return on capital exceeds all other standards. This indicates that Delphi's future performance is likely to increase at a rate above the other standards.

Finally, Chart 2 indicates Delphi's stock performance relative to the S\&P 500 stock index for the past 5 years. Delphi has consistently underperformed the S\&P 500 index although much of the Delphi's performance can be attributed to the weak economy and very weak automotive demand; other lean leaders such as Toyota and WalMart have outperformed the S\&P Index (MSN Money). At this point, based on the stock performance and other financial indicators, the expected financial impacts of implementing lean manufacturing have not materialized for Delphi.

\section{Delphi: Explanations and Potential Causes of Variance}

As can be seen from the financial performance metrics presented for Delphi, the company has not yet achieved a number of the expected financial benefits from adopting the lean manufacturing system. While the indicators for quality and lead time for new products are positive; inventory turns, production lead times, conversion costs, and productivity would at best be considered neutral and more likely be considered negative in relationship to the expectations of lean manufacturing. There are several potential causes that explain the variance between the expected results and the current results. 


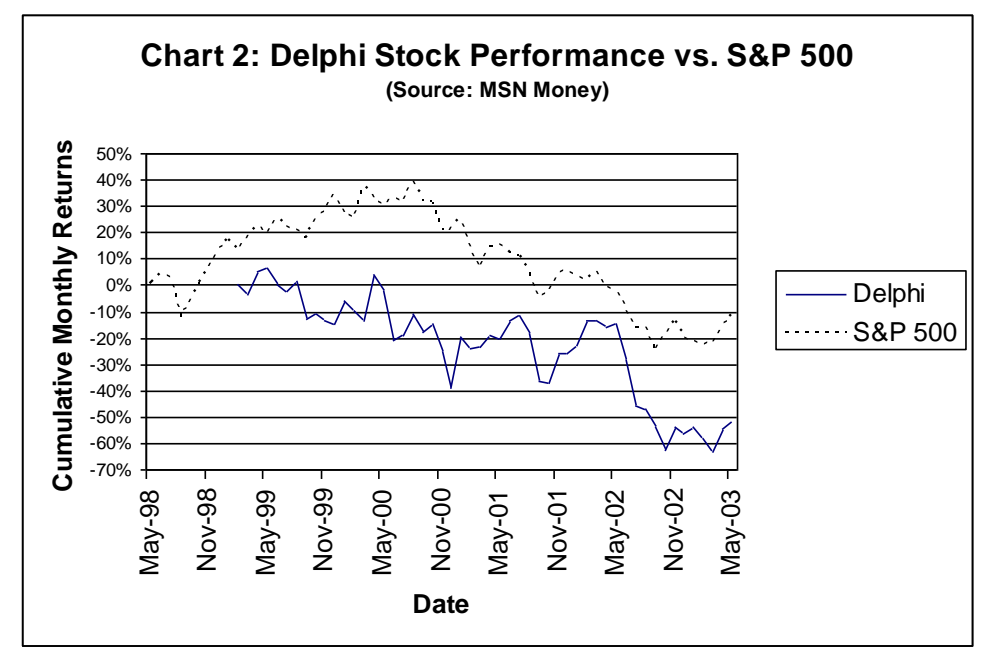

To begin with, there is a significant difference between changing a company's manufacturing system and changing the underlying culture of the company. Major organizational change, like adopting lean manufacturing, will often lead to resistance from the current company culture (Dessler 153). This resistance can be caused by many issues including fear of the unknown or perceived threats to personal power, security, and influence. The increase in productivity associated with lean manufacturing and the drive for a flatter organization can often result in job loss. The focus on team-based efforts can force the sharing of tacit knowledge of employees, reducing their power. Because lean manufacturing results depend on an organizational culture that is driven to reduce "muda", the full benefits of lean manufacturing will not be realized until this culture has been developed. Although Delphi has been around for many years, the organizational spilt between GM and Delphi is relatively recent. It can only be expected that the company culture will require more time to adapt to the total concept of lean manufacturing.

Lean manufacturing's effectiveness is also based to a large extent on the network effect. The network effect represents the increase in individual value resulting from the addition of new users to a network (Baye 486). For example, a single telephone has no value; however, connect the telephone to a network of a thousand phones and the value has increased. As more phones are added to the network, more value is added to the individual phone. Delphi represents one point in the network of the supply chain. By adopting lean manufacturing Delphi can gain some positive results but if their supply chain continues to do business the old way, they will still have quality, cost, and delivery problems. A survey of manufacturers found that only $34 \%$ recognize the need for a lean approach and that $41 \%$ are either not familiar with lean manufacturing or are not planning to implement it (Quality 12). With so much of the supply base not focused on lean manufacturing systems, it is likely that the network effect of lean manufacturing for Delphi would be small. Delphi has recognized this point and is aggressively attempting to initiate lean systems in its supply base (Jewett 48). One of the goals of this program is an attempt to reduce the number of suppliers to Delphi from the current level of 7,000 to about 1,000 by 2008.

A third reason that lean systems may not be showing positive financial impacts in the short term is that past plant designs and locations may limit the amount of lean imbedding. When Honda established their plant in Marysville, Ohio, over 75\% of the U.S. suppliers were located within 150 miles of the facility (Russell 278). Such proximity will allow for more deliveries, lower inventories, and closer cooperation between the supplier and the customer. While at one time many of Delphi's plants were located in close proximity to assembly facilities, many of their brake manufacturing facilities are still located in Dayton, Ohio, a 4-6 hour drive from assembly plants in Michigan, Illinois, and Tennessee. In addition, a number of Delphi's facilities are quite old. While plant layouts can be changed, the time and cost required to change a facility must be carefully planned so that production and cash flow are not interrupted. 
Finally, past labor contracts and commitments are masking the impacts that lean manufacturing can have on the financial position of Delphi. Currently, as much as $\$ 1,000$ of vehicle cost represents pension and healthcare commitments of the auto manufacturer. Delphi, once part of GM, also has substantial pension and healthcare burdens (Delphi). This part of the cost structure of Delphi can only be impacted by lean manufacturing in the longterm. Although Delphi has made a significant commitment to lean manufacturing, it will take more time for this commitment to develop into a sustainable competitive advantage and a positive financial impact.

\section{JOHNSON CONTROLS}

Johnson Controls produces a wide variety of products for the automotive and building industry. Products manufactured for the automotive industry include car seats, batteries, and interior systems. Building products include products such as environmental control systems for commercial buildings. More than a third of all automobiles produced in North America are equipped with some form of Johnson Controls' electronics and their products can be found in retail stores such as Sears and Auto Zone (Johnson Controls). Johnson Controls was founded 1885 by Warren S. Johnson in Milwaukee, Wisconsin and has reached sales of \$20 billion in 2002 (MSN Money).

\section{Johnson Control: Commitment to Lean}

Johnson Controls has been awarded with 8 Shingo Awards since 1996. Table 6 presents the years and specific allocation of the Shingo Awards that Johnson Controls plants have received. Several of its plants have been recognized for their organizational focus on the key aspects of lean manufacturing. Their latest prize, awarded in May 2001, went to a foam production plant in Greenfield, Ohio (Johnson Controls). Johnson Controls has implemented many tactics to help ensure the positive impacts that lean manufacturing can provide. An example of this is the company-adopted acronym CHESS, or Company Health, Environmental and Safety System (Johnson Controls). This procedure involves a series of self-audits and process improvement innovations along with consequent implementation. When considering the awards and company focus on continuous improvement, Johnson Controls is a prime candidate for the financial analysis of a "lean manufacturer."

Table 6: Shingo Awards to Johnson Controls
\begin{tabular}{rcccccccc} 
Year & 1996 & 1997 & 1998 & 1999 & 2000 & 2001 & Total \\
\hline \# of Plants & 2 & 4 & 1 & 0 & 0 & 1 & 8
\end{tabular}

\section{Johnson Control: Presentation of Metrics and Comments}

Table 7 reflects the inventory turnover rates of Johnson Controls versus both the industry average and other industry leaders. Inventory turnover is defined as cost of sales for the past 12 months divided by the average inventory. Although Johnson Controls falls short of the goal listed for inventory turns in Table 1 for a lean manufacturer, it is still considerably higher than both the industry average and its competitors. At a rate of 24.4, its turnover is twice as high as the industry and Toyota, the creator of lean manufacturing, as well as being three times higher than both the S\&P 500 and Wal-Mart.

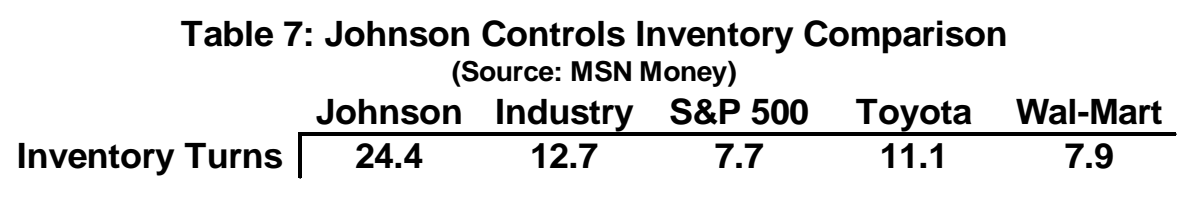

As stated earlier, with the implementation of lean manufacturing methods lead times should drop significantly when compared to more dated production methods. Consequently, there should be a drop in both 
finished goods and in total inventory. According to Table 8, inventory levels are increasing but relative to the increase in net sales the total inventory is actually decreasing. This can be seen with the decline in net inventory as a percent of net sales. This ratio shows the positive contribution that lean practices are making to Johnson Control's total inventory. Without lean methods the inventory would increase at the same rate or at a higher rate than net sales.

Table 8: Johnson Controls Inventory Valuations

\begin{tabular}{|c|c|c|c|c|c|}
\hline Year & $\begin{array}{l}\text { Finished } \\
\text { Goods } \\
\text { (Millions \$) }\end{array}$ & $\begin{array}{c}\text { Net } \\
\text { Inventory } \\
\text { Value } \\
\text { (Millions \$) }\end{array}$ & $\begin{array}{l}\text { Net Sales } \\
\text { (Millions \$) }\end{array}$ & $\begin{array}{c}\text { Net } \\
\text { Inventory } \\
\text { as } \% \text { of } \\
\text { net sales }\end{array}$ & $\begin{array}{c}\text { Estimated } \\
\text { Inventory } \\
\text { Turns }\end{array}$ \\
\hline 1998 & 157.3 & 428.2 & 12,587 & $3.40 \%$ & 29.4 \\
\hline 1999 & 174.5 & 524.6 & 16,139 & $3.25 \%$ & 30.8 \\
\hline 2000 & 177.4 & 569.5 & 17,155 & $3.32 \%$ & 30.1 \\
\hline 2001 & 203.8 & 577.6 & 18,427 & $3.13 \%$ & 31.9 \\
\hline 2002 & 242.2 & 653.6 & 20,103 & $3.25 \%$ & 30.8 \\
\hline
\end{tabular}

Chart 3 also indicates that for the past 4 years inventory with respect to sales has been decreasing which is a positive reflection of lean manufacturing.

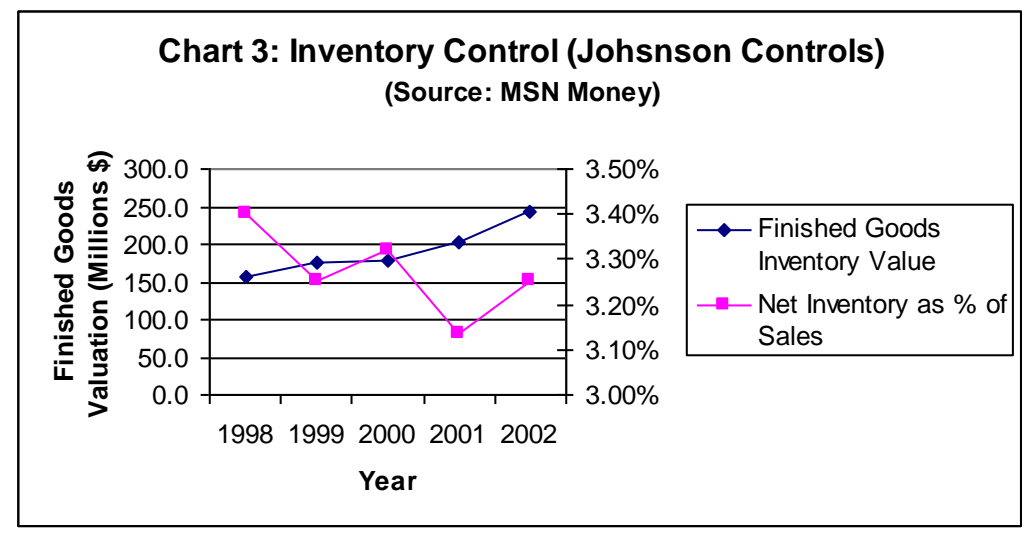

A metric comparison of conversion costs of Johnson Controls versus the industry and industry leaders is illustrated below. Johnson Controls is ahead of the industry average with respect to income per employee, but it lags behind S\&P 500 and Toyota. Although Johnson Controls and Wal-Mart are in the same standing, higher revenue per employee puts Johnson Controls at a slight advantage. Although there is undoubtedly room for improvement with respect to Johnson Controls conversion costs, they are still fairly new to the lean manufacturing concept. Johnson Controls is currently in the process of marketing the concept of lean to many of its suppliers. This will have positive effects in the near future once the lean concept has been adopted and savings passed on to Johnson Controls.

Johnson Controls has been a name associated with a host of environmental awards. It has been earned such awards as Energy Star Programs "Partner of the Year" and "Ally of the Year." It has also received an award from the National Energy Resources Organization the Research and Development Excellence Award, due in part for their collaboration in a fuel-efficient hybrid car (Johnson Controls). It is also a co-sponsor of the annual Energy Efficiency Forum held in Washington, D.C. 
Table 9: Johnson Controls Conversion Cost Comparison

(Source: MSN Money)

\section{Income per Employee Revenue per Employee Return on Assets Return on Capital}

\begin{tabular}{|cccccc|}
\hline Johnson & Industry & S\&P 500 & Toyota & Wal-Mart \\
\hline $\begin{array}{c}\text { W,000 } \\
\$ 4,000\end{array}$ & $\$ 12,000$ & $\$ 17,000$ & $\$ 6,000$ \\
$\$ 191,000$ & $\$ 170,000$ & $\$ 290,000$ & $\$ 436,000$ & $\$ 175,000$ \\
$5.3 \%$ & $3.2 \%$ & $1.3 \%$ & $2.9 \%$ & $8.5 \%$ \\
$12.0 \%$ & $7.1 \%$ & $3.6 \%$ & $5.1 \%$ & $13.6 \%$
\end{tabular}

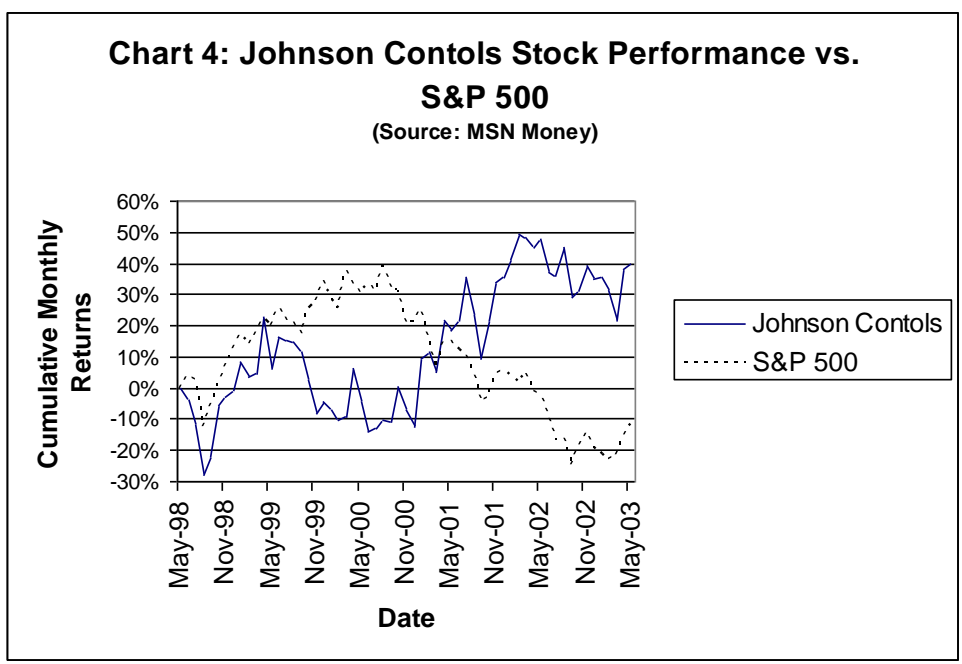

Productivity metrics can also be seen in Table 9. Johnson Controls is second to only Wal-Mart with respect to return on capital. Johnson Controls has also produced positive dividends for 27 years consecutively (Johnson Controls).

Chart 4 illustrates Johnson Controls' stock performance when compared to the S\&P 500 stock index spanning the last 5 years. As can be seen in the chart Johnson Controls stock has performed much better than the S\&P 500 index since January 2001. Investors obviously have confidence in Johnson Controls ability to control costs and sustain efficient processes. This is even more impressive given the state of the automotive markets during this time period.

\section{Johnson Control: Explanation and Potential Causes of Variance}

Johnson Controls has experienced benefits from lean manufacturing; however, there are areas of opportunity and improvement for the company. It is important to examine what those areas of opportunity are and why these areas are not fitting the goals of lean manufacturing.

Johnson Controls has vastly improved its inventory turnover. This is due partially to increased sales over the past several years. The reduction of inventory has lowered its internal costs and therefore producing more profit at the end of the year. Its dividends and sales have been consecutively increasing for more than a decade. Johnson Controls has a major area of opportunity with respect to conversion costs. Regardless of its successes, none of these statistics are reaching the limits that are set by lean manufacturing.

A few key barriers have impaired the major gaps identified. First, it must be considered that Johnson Controls is still fairly new to the lean manufacturing integration process. Lean manufacturing was created decades 
ago to benefit Toyota. It took years for Toyota to reap the benefits of this new program because lean manufacturing is not only a change in the manufacturing process but of the company culture. Since Johnson Controls has been in operation for more than a decade habits may be more engrained in the employees. For this reason it may take longer to confidently embrace drastic changes set forth by a lean manufacturing system.

Another explanation for underperformance versus the lean targets is the supply chain. Johnson Controls is a global leader in the automotive industry and it has domestic automobile manufacturers as its main customers. The domestic manufacturers were historically mass producers but Johnson Controls has been lean longer than other companies and they are beginning to see positive results from the integration of their supply chain. These results due to this network affect will begin to compound in the coming years and allow Johnson Controls' results to surge closer to the expected targets of lean producers. (Johnson Controls).

\section{CONCLUSION}

Lean manufacturing was developed out of necessity in Japan to compete with larger more efficient producers. The time has come in America where American Manufacturers must now compete with large more efficient producers worldwide and especially in Japan. Results gained from lean manufacturing methods have been proven to reduce costs and material staging space while at the same time improving quality. These are the key measurements for any production process in terms of being more efficient and more profitable than competitors.

The results of implementation of lean practices can vary depending on factors present at the firm. Delphi Corporation has seen positive results in some financial indicators but they have not yet reached the numbers of efficiency expected by lean producers. Delphi has received awards in product quality and technology cycle time and has had 12 of 68 plants in the US, Canada, and Mexico awarded the Shingo Prize for Excellence in Manufacturing. Delphi, however, has experienced lower than expected results in areas such as conversion costs, inventory levels, revenue per employee, and return on assets. The low levels of these metrics may be attributed to the difficulty in cultural change to the lean processes, lack of supplier participation, logistical issues related to plant location, and past labor contracts binding the firm to paying large pension funds. Delphi has also seen its stock under perform the S\&P 500 index despite all of its effort to implement lean manufacturing practices.

Johnson Controls has received several awards for its environmental conscious technology in the building of a fuel-efficient hybrid car and has had eight production facilities awarded the Shingo prize for Excellence in Manufacturing. Johnson Controls, while falling short of the inventory turns target of 50 per year, exceeds the rest of their industry by twice the number of turns and three times as many turns as the S\&P 500 and Wal-Mart. Johnson Control's inventory levels have increased since implementing lean processes but the turnover rate has increased indicating improvement and a decrease in net inventory as a percent of net sales. Income per employee at Johnson Controls is higher than the industry average but still has room for improvement in comparison to the S\&P 500. The stock performance of Johnson Controls has exceeded the performance of the S\&P 500 index despite a downturn in the economy in 2001. Johnson Controls has experienced many successes since implementing lean practices and has been able to lower costs associated with inventory thus increasing profits at the year-end. The gaps in achieving benchmark financial ratios at Johnson Controls such as lean producing targets of 50 inventory turns can be attributed to cultural habits and the network affect. While the network affect is beginning to achieve desired results for Johnson Controls it has not yet begun to compound as rapidly as it should in the coming years as more suppliers adopt lean manufacturing. The network affect is the key to the success rate that firms will gain from the implementation of lean practices. Without the supply chain being lean there will be difficulties in achieving targeted goals as can be seen in the financial results of Delphi Corporation.

Delphi and Johnson Controls have had successes with lean manufacturing practices but have also had difficulties achieving the targets set forth for lean manufacturers. For both companies the difficulties lie in the cultural changes required for lean implementation and in pushing lean practices down through the supply chain. Once the obstacles for these two areas have been overcome the cost reductions and efficiencies from lean implementation will be further recognized. In the interim financial yardsticks can be effected positively but will not 
approach target levels of Japanese lean manufacturers who have embraced the lean concept for more than 50 years and have planted the culture deep into the habits of the entire supply chain.

\section{REFERENCES}

1. Baye, Michael R. Managerial Economics and Business Strategy. New York: McGraw-Hill, 2003.

2. Boudette, Neal E., Sholnn Freeman, and Gregory Zuckerman "Chrysler's U-Turn on Bond Issue Highlights Turmoil in Company”. Wall Street Journal 5 June 2003: A1.

3. Cre8tive Training, Inc. San Juan Capistrano, CA. 1985 <http://www.cre8tivetraining.com/lean>.

4. Delphi. Troy, MI. 2 June $2003<$ http://www.delphi.com/>.

5. Dessler, Gary. A Framework For Human Resource Management. Upper Saddle River: Pearson Education, 2002.

6. Henderson, Bruce A., and Jorge L. Larco. "Lean Transformation: How To Change Your Business Into A Lean Enterprise." Richmond, VA: The Oaklea Press, November 2000.

7. Jewett, Dale. "Delphi's Mission: Spread The Lean Gospel.” Automotive News, 12 May 2003.

8. Johnson Controls, Inc. Milwaukee, WI. 2003 <http://www.johnsoncontrols.com>.

9. Jordan, Bradford, Stephen A. Ross, and Randolph W. Westerfield. "Essentials of Corporate Finance." New York: McGraw-Hill-Irwin, 2001.

10. Manufacturers’ Knowledge Of Lean Varies” Quality May 2003: 12.

11. Mid-America Manufacturing Technology Center (MAMTC). Overland Park, KS. October 1991 $<$ http://www.mamtc.com/lean>.

12. "MSN Money: Media General Financial Services." MSN Money. 28 May 2003. $\langle$ http://moneycentral.msn.com/home.asp>.

13. Price, Dr. John. "Warren Buffet Meets Sherlock Holmes Stock market Software And Education." Valuesoft. 6 June $2003<$ http://www.sherlockinvesting.com/articles/capital.htm>.

14. Process Professionals Incorporated (PPI Consulting). $\quad$ St. Louis, MO. 2002 <http://www.ppiconsulting.com>.

15. Russell, Roberta S., and Bernard W. Taylor III, Operations Management. Upper Saddle River: Pearson Education, 2003.

16. "Shingo Prize for Excellence in Manufacturing." Utah State University. 28 May 2003. $<$ http://www.shingoprize.org/> 